\title{
Relation between abdominal subcutaneous fat tissue thickness and inflammatory markers during pregnancy
}

Nermin Köşüşำ, Aydın Köşüşำ Nilgün Turhan²

${ }^{1}$ Fatih University, Ankara, Turkey

${ }^{2}$ Muğla University, Ankara, Turkey

Submitted: 4 January 2012

Accepted: 7 April 2012

Arch Med Sci 2014; 10, 4: 739-745

DOI: 10.5114/aoms.2014.44865

Copyright $\odot 2014$ Termedia \& Banach

\author{
Corresponding author: \\ Nermin Köşüş MD \\ Turgut Özal University \\ Alparslan Türkeş Cad. No: 57 \\ Emek \\ 06510 Ankara, Turkey \\ Phone: +90 3122035555 \\ E-mail: nerminkosus@gmail. \\ com
}

\begin{abstract}
Introduction: Subcutaneous abdominal fat thickness (SCFT) is important for predisposition to metabolic and cardiovascular diseases. Our aim was to evaluate maternal SCFT and metabolic changes (such as insulin resistance and high inflammatory markers) during pregnancy.

Material and methods: A total of 92 pregnant women between 24-28 weeks of gestation were enrolled in the study. The SCFT was measured by ultrasonography and patients were divided into 2 groups according to thickness of maternal SCFT and body mass index (BMI). Groups were compared with each other for oral glucose loading test (OGL) results, and for haematological, biochemical and fetal biometric parameters.

Results: After analysis of frequency for SCFT, the most appropriate cut-off value for grouping patients was found to be $15 \mathrm{~mm}$ for SCFT. In 48 cases SCFT was over $15 \mathrm{~mm}$. High C reactive protein (CRP) was found in $47.9 \%$ (23) of cases with SCFT over $15 \mathrm{~mm}$. Serum haemoglobin $\mathrm{A}_{1 \mathrm{c}}\left(\mathrm{HbA}_{1 \mathrm{c}}\right)$ level was significantly correlated with SCFT thickness. The most important factors for determination of OGL level were found to be serum $\mathrm{HbA}_{1 \mathrm{c}}$ level, BMI and SCFT. In obese subjects (BMI $\geq 25 \mathrm{~kg} / \mathrm{m}^{2}$ ), levels of inflammatory markers and SCFT thickness were higher. The CRP and $\gamma$-glutamyltransferase (GGT) levels were significantly correlated with BMI and SCFT.

Conclusions: High SCFT during pregnancy is associated with elevated inflammatory marker levels and $\mathrm{HbA}_{1 \mathrm{c}}$. Pregnant women with thicker SCFT may be susceptible to the development of metabolic complications of pregnancy, such as gestational diabetes mellitus (GDM) and hypertension, as well as risk of future metabolic and cardiovascular disease.
\end{abstract}

Key words: pregnancy, adipose tissue, inflammation, subcutaneous fat tissue.

\section{Introduction}

Obesity plays a major role in the pathogenesis of several medical problems including metabolic and cardiovascular disease [1]. Although the body mass index (BMI) is a useful indicator of overall adiposity [2], it is still unclear whether the visceral or the subcutaneous part of abdominal fat is more deleterious for predisposition to metabolic and cardiovascular disease. The subcutaneous fat (SCFT) is different from the visceral adipose tissue (VAT) in the production of adipocytokines [3-5]. The SCFT releases 2-3 times more leptin than VAT [6]. There are some studies reporting that subcutaneous fat is associated with insulin resistance $[7,8]$ 
although the role of SCFT in relation to insulin resistance is not well recognized [9].

There is no study in the literature about maternal subcutaneous fat thickness and metabolic changes (such as insulin resistance and high inflammatory markers) during the $2^{\text {nd }}$ trimester of pregnancy. There is a marked increase in plasma levels of cholesterol and triacylglycerol during pregnancy, but it is unknown whether maternal subcutaneous fat is associated with these changes or whether some metabolic complications related to subcutaneous fat thickness are similar in pregnant and non-pregnant women. There might be an association between SCFT thickness and some pregnancy-related complications. Subcutaneous fat measurements over a cut-off point might help us to identify risk groups in which early and accurate detection of gestational metabolic disorders (gestational diabetes or hypertension) is essential.

Measurement of abdominal subcutaneous fat by ultrasound is an easy and non-invasive method. It also avoids the use of ionizing radiation. In this study we measured SCFT thickness in 24-28 week pregnant women and compared the results with oral glucose loading test results as well as haematological, biochemical and fetal biometric parameters to determine whether they might be early markers of gestational metabolic disorders.

\section{Material and methods}

This prospective cohort study was carried out at the Fatih University Faculty of Medicine, Obstetrics and Gynaecology Department, Ankara. Inclusion criteria were: maternal age between 20-35 years, singleton pregnancy with a live fetus, gestational age 24-28 weeks, and healthy women without any medical disorders. The exclusion criteria were: smokers or drug users in the index pregnancy, and women with a previous history of gestational diabetes mellitus (GDM) or any other systemic disease. Written informed consent was obtained from all subjects. Approval for this study was obtained from the Local Institutional Review Board of the Faculty of Medicine, Fatih University.

Body mass index was calculated as weight $(\mathrm{kg}) /$ height $\left(\mathrm{m}^{2}\right)$ in all cases. All measurements were obtained in the morning, after overnight fasting. Since our study population consisted of pregnant women, overnight fasting for $10 \mathrm{~h}$ was recommended before blood testing. Patients were advised not to eat anything after $10.00 \mathrm{pm}$ and come for testing at or after $8.00 \mathrm{am}$. The study was performed using an Aloka Prosound SSD3500SX (Aloka Holding Europe AG, Switzerland) 3.5 $\mathrm{MHz}$ transabdominal probe. All ultrasound examinations were performed by the same operator. The gestational age was calculated by the modified Naegele's rule. Last menstrual period-derived gestational age was compared with ultrasound-derived gestational age using fetal biometric parameters. Subcutaneous fat depth was measured from the subcutaneous fat layer to the outer border of the rectus abdominis muscle at the level of the linea alba [10]. After analysis of frequency for SCFT, the most appropriate cut-off value for grouping patients was found to be $15 \mathrm{~mm}$ for SCFT. This cut-off point was also very near to the median value of SCFT thickness. Patients were divided into 2 groups according to this value and compared with each other.

Venous blood samples were collected in the morning, after overnight fasting, from the brachial vein of the patients. Blood samples were immediately centrifuged, and plasma and serum samples were kept at $-70^{\circ} \mathrm{C}$ until laboratory testing. Glucose was measured with a standard hexokinase reference method (Cobas Integra 800 analyser, Roche Diagnostics, Basel, Switzerland). An abnormal $50 \mathrm{~g}$ oral glucose loading test (OGL) was defined at a conventional cut-off point of $\geq 130 \mathrm{mg} / \mathrm{dl}$ and a $100 \mathrm{~g}, 3 \mathrm{~h}$ oral glucose tolerance test was applied to the patients with an OGL result over the cut-off point [11]. Total cholesterol (TC), high-density lipoprotein cholesterol (HDL-C), very-low-density lipoprotein cholesterol (VLDL), blood urea nitrogen (BUN), creatinine, $\gamma$-glutamyltransferase (GGT) and triglycerides (TG) were measured with enzymatic colour tests (Cobas Integra 800 analyser, Roche Diagnostics, Basel, Switzerland). Low-density lipoprotein cholesterol (LDL-C) was calculated according to the Friedewald formula [12]. Haemoglobin $A_{1 c}\left(\mathrm{HbA}_{1 c}\right)$ was determined by means of high performance liquid chromatography (Shimadzu, Kyoto, Japan) [13]. C-reactive protein (CRP) levels were measured by nephelometry (Beckman coulter Image, US) [14].

A power analysis was conducted before recruitment. Using an $\alpha$ level of $0.05, \beta$ level of 0.20 , a power of $80 \%$ and effect size of 0.60 , a total sample size of 92 cases was needed for the study.

\section{Statistical analysis}

Statistical analyses were conducted using SPSS for Windows, version 15.0 (SPSS Inc., Chicago, IL, USA). Descriptive statistics are presented as mean values $\pm S D$ and median (interquartile range; $I Q R$ ). The $\chi^{2}$ test was used for comparison of categorical data. Independent samples $t$ test was used for comparison of groups which were fit to a normal distribution. For groups that were not distributed normally, Mann-Whitney test was used for comparison. Spearman correlation coefficients were used to estimate the correlations between biochemical and obesity-related parameters and clinical characteristics. Backward multiple linear 
regression analysis was performed to investigate the relationship between biochemical parameters as a dependent variable and obesity-related parameters and lipid profile as independent variables. Value of $p<0.05$ was considered to be statistically significant.

\section{Results}

A total of 92 pregnant women were enrolled in the study. Patients were divided into 2 groups according to thickness of maternal SCFT. The SCFT was over the cut-off point (over $15 \mathrm{~mm}$ ) in $52.2 \%$ (48) of cases. Women with SCFT $>15 \mathrm{~mm}$ had higher BMI than women with lower SCFT (27.34 $\mathrm{kg} / \mathrm{m}^{2}$ vs. $\left.23.88 \mathrm{~kg} / \mathrm{m}^{2}, p<0.001\right)$. Comparison of
SCFT subgroups revealed a significant difference in terms of OGL and GGT levels, which were higher in patients with high SCFT ( $p=0.003, p=0.018$ ). Comparison for other parameters revealed no significant difference. The distribution of groups and demographic data of cases are shown in Table I.

The BMI was over $25 \mathrm{~kg} / \mathrm{m}^{2}$ in $66.3 \%$ (61) of all cases. The SCFT was significantly higher in women with high BMI (over $\left.25 \mathrm{~kg} / \mathrm{m}^{2}\right)(p<0.001)$. The SCFT was found to be $>15 \mathrm{~mm}$ in $72.4 \%$ (44) of women with high BMI. The OGL was found to be significantly higher in women with $\mathrm{BMI}>25 \mathrm{~kg} / \mathrm{m}^{2}$ $(p=0.006)$. Similarly, estimated fetal weight (EFW) was significantly higher in women with high BMI ( $p=0.012)$ (Table II).

Table I. Comparison of patients according to SCFT thickness

\begin{tabular}{|c|c|c|c|c|}
\hline Variables & $\begin{array}{l}\text { All cases } \\
(n=92)\end{array}$ & $\begin{array}{l}<15 \mathrm{~mm} \\
(n=44)\end{array}$ & $\begin{array}{l}\geq 15 \mathrm{~mm} \\
(n=48)\end{array}$ & Value of $p$ \\
\hline Age [years] & $28(7)$ & $27(5.5)$ & $28.5(7.75)$ & 0.936 \\
\hline BMI $\left[\mathrm{kg} / \mathrm{m}^{2}\right]$ & $26.35(3.67)$ & $23.88(3.12)$ & $27.34(4.15)$ & $<0.001$ \\
\hline Gravidity, $n$ & $2(1)$ & $2(1)$ & $2(1)$ & 0.768 \\
\hline Parity, $n$ & $1(1)$ & $1(1)$ & $0(1)$ & 0.259 \\
\hline Gestational age [week] & $25.25(2.13)$ & $25.35(2.73)$ & $25.15(1.45)$ & 0.564 \\
\hline $\mathrm{BPD}[\mathrm{mm}]$ & $64(6.25)$ & $64.15(9.25)$ & $63.5(5.8)$ & 0.841 \\
\hline $\mathrm{FL}[\mathrm{mm}]$ & $46(3.25)$ & $46(5.5)$ & $46(2.25)$ & 0.662 \\
\hline $\mathrm{AC}[\mathrm{mm}]$ & $208(23.5)$ & $209.5(25.75)$ & $205(23.5)$ & 0.760 \\
\hline EFW [g] & $805(209.5)$ & $814(224.75)$ & $776(232.5)$ & 0.944 \\
\hline SCFT $[\mathrm{mm}]$ & $15.25(8.08)$ & $11.2(3)$ & $18.95(5.18)$ & $<0.001$ \\
\hline $\log$ CRP $[\mathrm{mg} / \mathrm{l}]$ & $0.71 \pm 0.28$ & $0.61 \pm 0.17$ & $0.80 \pm 0.33$ & 0.002 \\
\hline $\log \mathrm{HbA}_{1 \mathrm{c}}[\%]$ & $0.66 \pm 0.04$ & $0.64 \pm 0.04$ & $0.67 \pm 0.04$ & 0.001 \\
\hline $\mathrm{FBS}[\mathrm{mg} / \mathrm{dl}]$ & $91(18.50)$ & $95(14.75)$ & 99 (14) & 0.435 \\
\hline Urea [mg/dl] & $15.6(4.50)$ & $15.35(4.65)$ & $15.71(4.45)$ & 0.799 \\
\hline Creatinine [mg/dl] & $0.4(0.1)$ & $0.4(0.1)$ & $0.4(0.1)$ & 0.883 \\
\hline TC [mg/dl] & $238.66 \pm 46.65$ & $240.50 \pm 51.08$ & $238.23 \pm 43.28$ & 0.572 \\
\hline TG [mg/dl] & $191.11 \pm 74.88$ & $186.95 \pm 63.34$ & $199.29 \pm 88.96$ & 0.410 \\
\hline $\mathrm{HDL}-\mathrm{C}[\mathrm{mg} / \mathrm{dl}]$ & $70.74 \pm 17.00$ & $68.35 \pm 14.90$ & $73.29 \pm 19.74$ & 0.647 \\
\hline LDL-C [mg/dl] & $129.55 \pm 40.46$ & $134.55 \pm 45.12$ & $125 \pm 35.81$ & 0.427 \\
\hline VLDL [mg/dl] & $37.79 \pm 15.03$ & $36.90(12.76)$ & $39.47 \pm 17.82$ & 0.397 \\
\hline AST [U/I] & $14(4.25)$ & $14.5(4)$ & $14(4.5)$ & 0.674 \\
\hline ALT [U/I] & $12(7.25)$ & $13(6.75)$ & $12(6.5)$ & 0.513 \\
\hline GGT [U/I] & $9.57 \pm 3.79$ & $8.54 \pm 2.35$ & $10.82 \pm 4.86$ & 0.018 \\
\hline $\mathrm{OGL}[\mathrm{mg} / \mathrm{dl}]$ & $109(36.5)$ & 99 (25.5) & 116.5 (37.5) & 0.003 \\
\hline
\end{tabular}

$B M I$ - body mass index, BPD - biparietal diameter, FL - femur length, AC - abdominal circumference, EFW - estimated fetal weight, SCFT - subcutaneous fat tissue, CRP - C-reactive protein, HbA $A_{1 c}$ - haemoglobin $A_{1 c^{\prime}} F B S$ - fasting blood sugar, TC - total cholesterol, TG triglyceride, HDL-C - high-density lipoprotein cholesterol, $L D L-C$ - low-density lipoprotein cholesterol, VLDL-very low-density lipoprotein cholesterol, OGL - oral glucose loading test, $p<0.05$ significant 
Table II. Relation between BMI and maternal SCFT, $\log$ CRP and $\log \mathrm{HbA}_{1 c}$

\begin{tabular}{|lccc|}
\hline Variables & \multicolumn{2}{c|}{ BMI $\left[\mathrm{kg} / \mathrm{m}^{2}\right]$} & Value of $p$ \\
\cline { 2 - 4 } & $<25(n=31)$ & $\geq 25(n=61)$ & $<0.001$ \\
\hline SCFT $[\mathrm{cm}]$ & $11.55(4.75)$ & $16.60(6.20)$ & 0.059 \\
\hline Log CRP $[\mathrm{mg} / \mathrm{l}]$ & $0.63 \pm 0.2$ & $0.75 \pm 0.3$ & 0.252 \\
\hline Log HbA $\mathrm{A}_{1 \mathrm{C}}[\%]$ & $0.65 \pm 0.03$ & $0.66 \pm 0.05$ & 0.006 \\
\hline OGL & $100(26.25)$ & $116(41.75)$ & 0.012 \\
\hline EFW & $765.5(129)$ & $855.5(256.75)$ & \\
\hline
\end{tabular}

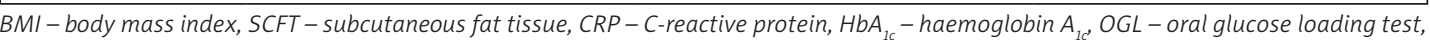
EFW - estimated fetal weight, $p<0.05$ significant

High CRP was found in $26.1 \%$ (24/92) of all cases, $32.8 \%(20 / 61)$ of women with high BMI (over $\left.25 \mathrm{~kg} / \mathrm{m}^{2}\right)$ and $47.9 \%(23 / 48)$ of women with high SCFT. The $\mathrm{HbA}_{1 \mathrm{c}}$ levels were within the normal range in all cases. To approximate a normal distribution, log transformed data of $\mathrm{HbA}_{1 c}$ and CRP were used in the analysis for CRP and $\mathrm{HbA}_{1 c}$ parameters. Log CRP and log $\mathrm{HbA}_{1 c}$ were significantly higher in women with high SCFT ( $p=0.002$ and $p=0.001$ ) (Table I). A borderline significant difference was observed between high BMI women versus low BMI in terms of log CRP $(p=0.059)$, although no significance was detected in terms of log $\mathrm{HbA}_{1 c}$ levels $(p=0.252)$.

Correlation analysis demonstrated a positive correlation between SCFT versus log $\mathrm{HbA}_{1 c}$, BMI and GGT. A significant correlation was observed between $\mathrm{HbA}_{1 c}$ vs. GGT and OGL. There were correlations of EFW with HDL, VLDL, TG, GGT and BMI (Table III).

Regression analysis showed that serum CRP levels were significantly associated with GGT and $\mathrm{BMI}(p=0.002$ and $p=0.037)$. There was a borderline association between CRP and SCFT ( $p=$ 0.063). Serum $\mathrm{HbA}_{1 \mathrm{c}}$ levels were significantly associated with SCFT thickness, TC, HDL, LDL and TG levels $(p<0.001, p=0.033, p=0.020, p=0.037$ and $p=0.019)$. The most important factors for determination of OGL level were $\mathrm{HbA}_{1 \mathrm{c}}, \mathrm{BMI}, \mathrm{SCFT}$, HDL and VLDL $(p=0.001, p=0.001, p=0.020$, $p=0.026$ and $p=0.004)$. The CRP had borderline significance for prediction of serum OGL results $(p=0.060)$.

\section{Discussion}

Many researchers have demonstrated that obesity is a state of chronic low-grade inflammation [15-18]. Inflammation itself may be the cause of obesity-related disorders. Inflammatory cytokines such as CRP are associated with obesity and in turn with increased risk for insulin resistance, diabetes mellitus, hypertension and dyslipidaemia [19-24].

Both VAT and SCFT are more strongly associated with high CRP in women than in men [25].
For VAT, multiple prior studies have demonstrated a relation between pre-diabetic hyperglycaemia and diabetes [26-29]. However, for SCFT few studies have yielded significant relations with glycaemic disorders. It was demonstrated that both SCFT and VAT were important correlates of insulin resistance and cardiometabolic risk factors, and that SCFT was associated with peripheral insulin action at least as strongly as intra-abdominal fat [9, 30-32]. The SCFT was positively correlated with age and all risk factors for metabolic syndrome. In addition to the presence of insulin resistance, leptin levels have been shown to be correlated with SCFT [33]. Leptin is associated with vascular dysfunction [34-37], which may be a mechanism for development of metabolic diseases.

The most important point in our study was that the study population consisted of pregnant women. Similarly to the non-pregnant population, we detected significantly higher CRP and $\mathrm{HbA}_{1 \mathrm{c}}$ levels in pregnant women with high SCFT. The CRP was significantly higher in pregnant women with a BMI over $25 \mathrm{~kg} / \mathrm{m}^{2}$ than in women with a normal BMI. We believe that the presence of SCFT $\geq 15 \mathrm{~mm}$ is a very strong predictor of high CRP and $\mathrm{HbA}_{1 \mathrm{c}}$ levels in pregnant women. In particular, higher values of SCFT during 24-28 weeks of gestation may be associated with pregnancy-related complications that could be observed during later periods of gestation, and measurement of SCFT might help us to identify risk groups.

The CRP level is associated with BMI and waist circumference, which is a crude index of visceral obesity $[15,38]$. However, correct measurement of waist circumference may be difficult during pregnancy. Also, correct calculation of BMI might be difficult due to weight gain and fluid retention. But SCFT can easily be measured in all pregnant women and this could correctly predict obesity and related complications during pregnancy.

Another important result of this study was the significantly higher GGT levels in women with SCFT over $15 \mathrm{~mm}$. Serum GGT level is a possible marker of oxidative stress $[39,40]$. It is associat- 
ed with development of metabolic syndrome and glucose intolerance [41-43]. It was suggested in previous studies that GGT is associated with VAT, but not with SCFT $[44,45]$. In this study we detected high serum GGT in patients with high SCFT thickness and a positive correlation was found between serum GGT and CRP levels.

Our findings underscore the positive association of SCFT with circulating markers of inflammation such as CRP and GGT. Thus, an increase in SCFT relative to overall body weight is associated with significantly elevated CRP concentrations, and this relation is also observed in pregnant women. Our results were similar to the results of the Framingham Heart Study [46]. They suggest that both abdominal SCFT and VAT have a role in inflammation and oxidative stress.

Another important point of this study was the detection of significantly higher OGL results in pregnant women with thicker SCFT. Women with high SCFT might be watched closely for the development of GDM during their pregnancy. We also observed significantly higher EFW in patients with high SCFT. In addition, there was a correlation between EFW versus lipid profile and BMI. These results may caution us about the prediction of macrosomia in patients with high SCFT and might help us in the prevention of macrosomia and related complications by regulation of lipid profile and dietary management.

A number of limitations of this study deserve comment. First, although the sample size is adequate, study groups were modest in size, so it is possible that the study was underpowered to detect differences between the groups. Secondly, we used only CRP and GGT as inflammatory and oxidative stress markers for prediction of metabolic disorders. However, other risk factors that could modify the condition must also be assessed separately. New studies with larger series including other inflammatory markers would increase the reliability and power of the study. And thirdly, perinatal results of cases were not evaluated. Long-term follow-up of cases and evaluation of perinatal results would be very important to correctly stratify the future risk. Addition of women with gestational diabetes to the study as another group would be more enlightening for the results of the study. However, we detected only one patient with GDM in our study. Therefore we only reported results concerning OGL.

In conclusion, CRP and GGT were significantly correlated with BMI and SCFT in pregnant women. These findings suggest that reducing obesity may prevent the elevation of cytokine levels, and as a result reduce the risk of metabolic complications during pregnancy, as well as the risk of future metabolic and cardiovascular disease.

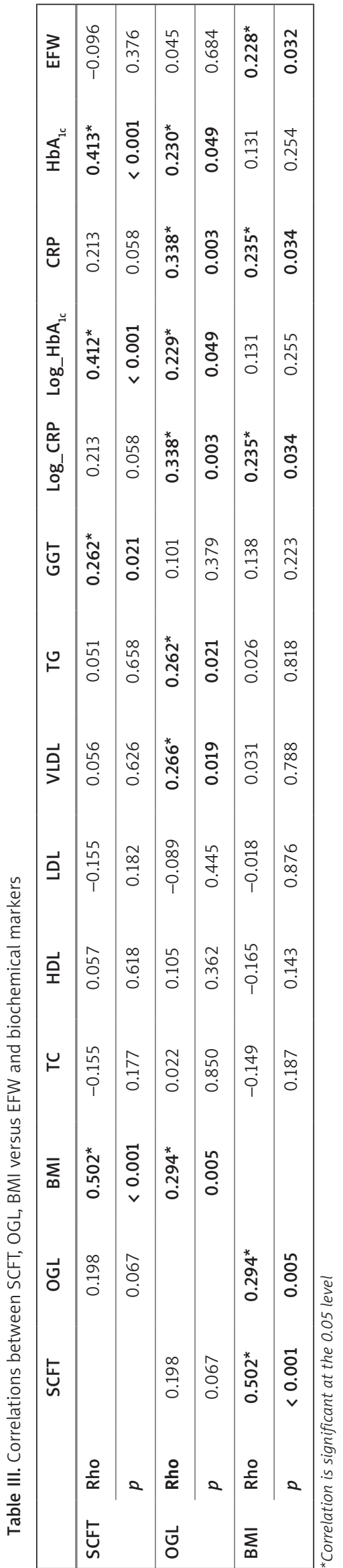




\section{References}

1. Lavie CJ, Milani RV, Ventura HO. Obesity and cardiovascular disease: risk factor, paradox, and impact of weight loss. J Am Coll Cardiol 2009; 53: 1925-32.

2. Ogden CL, Carroll MD, Curtin LR, McDowell MA, Tabak CJ, Flegal KM. Prevalence of overweight and obesity in the United States, 1999-2004. JAMA 2006; 295: 1549-55.

3. Ibrahim MM. Subcutaneous and visceral adipose tissue: structural and functional differences. Obes Rev 2010; 11: $11-8$.

4. Onat A, Avci GS, Barlan MM, Uyarel H, Uzunlar B, Sansoy $V$. Measures of abdominal obesity assessed for visceral adiposity and relation to coronary risk. Int J Obes Relat Metab Disord 2004; 28: 1018-25.

5. Yang X, Smith U. Adipose tissue distribution and risk of metabolic disease: does thiazolidinedione-induced adipose tissue redistribution provide a clue to the answer? Diabetologia 2007; 50: 1127-39.

6. Tritos NA, Mantzoros CS. Leptin: its role in obesity and beyond. Diabetologia 1997; 40: 1371-9.

7. Goel K, Misra A, Vikram NK, Poddar P, Gupta N. Subcutaneous abdominal adipose tissue is associated with the metabolic syndrome in Asian Indians independent of intra-abdominal and total body fat. Heart 2010; 96 : 579-83.

8. Kelley DE, Thaete FL, Troost F, Huwe T, Goodpaster BH. Subdivisions of subcutaneous abdominal adipose tissue and insulin resistance. Am J Physiol 2000; 278: 941-8.

9. Porter SA, Massaro JM, Hoffmann U, Vasan RS, O'Donnel CJ, Fox CS. Abdominal subcutaneous adipose tissue: a protective fat depot? Diabetes Care 2009; 32: 1068-75.

10. Stolk RP, Wink O, Zelissen PM, Meijer R, van Gils AP, Grobbee $\mathrm{DE}$. Validity and reproducibility of ultrasonography for the measurement of intra-abdominal adipose tissue. Int J Obes Relat Metab Disord 2001; 25: 1346-51.

11. American Diabetes Association. Diagnosis and classification of diabetes mellitus. Diabetes Care 2009; 32: 62-7.

12. Friedewald WT, Levy RI, Fredrickson DS. Estimation of the concentration of low density lipoprotein cholesterol in plasma without use of preparative ultracentrifuge. Clin Chem 1972; 18: 499-502.

13. Steffes M, Cleary P, Goldstein D, et al. Hemoglobin A1c measurements over nearly two decades: sustain ing comparable values throughout the Diabetes Control and Complications Trial and the Epidemiology of Diabetes Interventions and Complications study. Clin Chem 2005; 51: 753-8.

14. Dominici R, Luraschi P, Franzini C. Measurement of C-reactive protein: two high sensitivity methods compared. JCLA 2004; 18: 280-4.

15. Lemieux I, Pascot A, Prud'homme D, et al. Elevated C-reactive protein: another component of the atherothrombotic profile of abdominal obesity. Arterioscler Thromb Vasc Biol 2001; 21: 961-7.

16. Pannacciulli N, Cantatore FP, Minenna A, Bellacicco M, Giorgino R, De Pergola G. C-reactive protein is independently associated with total body fat, central fat, and insulin resistance in adult women. Int J Obes Relat Metab Disord 2001; 25: 1416-20.

17. Park HS, Park JY, Yu R. Relationship of obesity and visceral adiposity with serum concentrations of CRP, TNF-alpha and IL-6. Diabetes Res Clin Pract 2005; 69: 29-35.

18. Saijo Y, Kiyota N, Kawasaki Y, et al. Relationship between C-reactive protein and visceral adipose tissue in healthy Japanese subjects. Diabetes Obes Metab 2004; 6: 249-58.
19. Mokdad AH, Ford ES, Bowman BA, et al. Prevalence of obesity, diabetes, and obesity-related health risk factors, 2001. JAMA 2003; 289: 76-9.

20. Harris MM, Stevens J, Thomas N, Schreiner P, Folsom AR. Associations of fat distribution and obesity with hypertension in a bi-ethnic population: the ARIC study. Atherosclerosis Risk in Communities Study. Obes Res 2000; 8: 516-24.

21. Wilson PW, D’Agostino RB, Sullivan L, Parise H, KannelWB. Overweight and obesity as determinants of cardiovascular risk: the Framingham experience. Arch Intern Med 2002; 162: 1867-72.

22. Mathieu P, Lemieux I, Després JP. Obesity, inflammation, and cardiovascular risk. Clin Pharmacol Therap 2010; 87: 407-16.

23. Rocha VZ, Libby P. Obesity, inflammation and atherosclerosis. Nat Rev Cardiol 2009; 6: 399-409.

24. Festa A, D’Agostino R Jr, Tracy RP, Haffner SM. Elevated levels of acute-phase proteins and plasminogen activator inhibitor-1 predict the development of type 2 diabetes: the insulin resistance atherosclerosis study. Diabetes 2002; 51: 1131-7.

25. Thorand B, Baumert J, Doring A, et al. Sex differences in the relation of body composition to markers of inflammation. Atherosclerosis 2006; 184: 216-24.

26. Goodpaster BH, Krishnaswami S, Resnick H, et al. Association between regional adipose tissue distribution and both type 2 diabetes and impaired glucose tolerance in elderly men and women. Diabetes Care 2003; 26: 372-9.

27. Kanaya AM, Harris T, Goodpaster BH, Tylavsky F, Cummings SR. Adipocytokines attenuate the association between visceral adiposity and diabetes in older adults. Diabetes Care 2004; 27: 1375-80.

28. Hayashi T, Boyko EJ, Leonetti DL, et al. Visceral adiposity and the risk of impaired glucose tolerance: a prospective study among Japanese Americans. Diabetes Care 2003; 26: 650-5.

29. Boyko EJ, Fujimoto WY, Leonetti DL, Newell-Morris L. Visceral adiposity and risk of type 2 diabetes: a prospective study among Japanese Americans. Diabetes Care 2000; 23: 465-71.

30. Tulloch-Reid MK, Hanson RL, Sebring NG, et al. Both subcutaneous and visceral adipose tissue correlate highly with insulin resistance in African Americans. Obes Res 2004; 12: 1352-9.

31. Flier JS, Maratos-Flier E. Biology of obesity. In: Harrison's principle of internal medicine. 17th ed. Fauci AS, Braunwald E, Kasper DL, et al. (eds.). Mc Grow Hill company, Philadelphia 2008; 262-3.

32. Gautier JF, Milner MR, Elam E, Chen K, Ravussin E, Pratley RE. Visceral adipose tissue is not increased in Pima Indians compared with equally obese Caucasians and is not related to insulin action or secretion. Diabetologia 1999; 42: 28-34.

33. Ruhl CE, Everhart JE, Ding J, et al. Serum leptin concentrations and body adipose measures in older black and white adults. Am J Clin Nutr 2004; 80: 576-83.

34. Sundell J, Huupponen R, Raitakari OT, Nuutila P, Knuuti J. High serum leptin is associated with attenuated coronary vasoreactivity. Obes Res 2003; 11: 776-82.

35. Yamagishi S, Inagaki Y, Amano S, Okamoto T, Takeuchi M. Up-regulation of vascular endothelial growth factor and down-regulation of pigment epithelium-derived factor messenger ribonucleic acid levels in leptin-exposed cultured retinal pericytes. Int J Tissue React 2002; 24: 137-42. 
36. Cooke JP, Oka RK. Does leptin cause vascular disease? Circulation 2002; 106: 1904-5.

37. Singhal A, Faroogi IS, Cole TJ, et al. Influence of leptin on arterial distensibility: a novel link between obesity and cardiovascular disease? Circulation 2002; 106: 1919-24.

38. Yamada S, Gotoh T, Nakashima Y, et al. Distribution of serum C-reactive protein and its association with atherosclerotic risk factors in a Japanese population. Jichi Med School Cohort Study. Am J Epidemiol 2001; 153: 1183-90.

39. Lee DH, Blomhoff R, Jacobs Jr DR. Is serum gamma glutamyltransferase a marker of oxidative stress? Free Radic Res 2004; 38: 535-9.

40. Pompella A, Emdin M, Passino C, Paolicchi A. The significance of serum gamma-glutamyltransferase in cardiovascular diseases. Clin Chem Lab Med 2004; 42: 1085-91.

41. Andre P, Balkau B, Vol S, Charles MA, Eschwege E. Gamma-glutamyltransferase activity and development of the metabolic syndrome (International Diabetes Federation Definition) in middle-aged men and women: Data from the Epidemiological Study on the Insulin Resistance Syndrome (DESIR) cohort. Diabetes Care 2007; 30: 2355-61.

42. Andre P, Balkau B, Born C, Charles MA, Eschwege E. Three-year increase of gamma-glutamyltransferase level and development of type 2 diabetes in middle-aged men and women: the DESIR cohort. Diabetologia 2006; 49: 2599-603.

43. Lee $\mathrm{DH}, \mathrm{Ha} \mathrm{MH}$, Kim JH, et al. Gamma-glutamyltransferase and diabetes-a 4 year follow-up study. Diabetologia 2003; 46: 359-64.

44. Iwasaki T. Hepatic fat content-independent association of the serum level of gamma-glutamyltransferase with visceral adiposity, but not subcutaneous adiposity. Diab Res Clin Pract 2008; 79: 13-4.

45. Wallace TM, Utzschneider KM, Tong J, et al. Relationship of liver enzymes to insulin sensitivity and intra-abdominal fat. Diabetes Care 2007; 30: 2673-8.

46. Pou KM, Massaro JM, Hoffmann U, et al.; The Framingham Heart Study. Visceral and subcutaneous adipose tissue volumes are cross-sectionally related to markers of inflammation and oxidative stress. Circulation 2007; 116: 1234-41. 